\title{
Realidades e Possibilidades da Docência Orientada em Educação Física no Ensino de Jovens e Adultos
}

\section{Realities and Possibilities of Physical Education Oriented Teaching in Young and Adult Education}

\author{
Realidades y Posibilidades de la Docencia Orientada en Educación \\ Física en la Enseñanza de Jóvenes y Adultos
}

\author{
Leandra Costa da Costa ${ }^{1}$ \\ Gabriel Vielmo Gomes ${ }^{2}$ \\ Andressa Aparecida Araújo dos Santos ${ }^{3}$
}

\begin{abstract}
Resumo
A disciplina de Docência Orientada em Educação Física no curso de Licenciatura da Universidade Federal de Santa Maria/RS (UFSM), proporciona ao acadêmico a inserção na rede escolar e exercício da docência diante dos diferentes contextos educacionais atualmente. No caso específico da Educação de Jovens e Adultos (EJA), à docência orientada no curso de Licenciatura em Educação Física da UFSM, busca aproximar o acadêmico da realidade que encontramos na atual conjuntura educacional através do exercício da docência. Nesse sentido, o objetivo desse descrito busca analisar como a Educação Física na EJA contribui para o processo de formação dos acadêmicos. Para isso, analisou-se algumas práticas vivenciadas durante a Disciplina de Docência Orientada em Educação Física na EJA. Através das inserções nas escolas, foram encontradas as seguintes dificuldades: problemas sociais, obstáculos na contemplação, organização de conteúdos devido às diferentes faixas etárias, evasão, entre outros. Essas situações possibilitaram a aproximação à realidade escolar, estimularam a busca de metodologias adequadas para amenizar tais dificuldades enquanto futuros professores. Dessa maneira, constatouse que a Docência Orientada apresenta um momento essencial na formação inicial, contribuindo para a apropriação de conhecimentos acerca da docência em Educação Física com jovens e adultos, instigando a busca pela qualificação visando à prática docente bem como o enfrentamento das dificuldades evidenciadas.
\end{abstract}

Palavras-Chave: Docência; Educação Básica; Educação Física; EJA; Formação Inicial.

\section{Resumen}

La disciplina de Docencia Orientada en Educación Física en el curso de Licenciatura de la Universidad Federal de Santa María/RS (UFSM), proporciona al académico la inserción en la red escolar y ejercicio de la docencia ante los diferentes contextos educativos actualmente. En el caso específico de la Educación de Jóvenes y Adultos (EJA), a la docencia orientada en el curso de Licenciatura en Educación Física de la UFSM, busca acercar al académico de la realidad que encontramos en la actual coyuntura educativa a través del ejercicio de la docencia. En este sentido, el objetivo de este descripto busca analizar cómo la Educación Física en la EJA contribuye al proceso de formación de los académicos. Para ello, se analizaron algunas prácticas vivenciadas durante la Disciplina de Docencia Orientada en Educación Física en la EJA. A través de las inserciones en las escuelas, se encontraron las siguientes dificultades: problemas sociales, obstáculos en la contemplación, organización de contenidos debido a las diferentes edades, evasión, entre otros. Estas situaciones posibilitaron la aproximación a

\footnotetext{
${ }^{1}$ Doutora em Educação; Universidade Federal de Santa Maria; Santa Maria, Rio Grande do Sul, Brasil; lcostadacosta@hotmail.com)

${ }^{2}$ Bacharel em Educação Física, Universidade Federal de Santa Maria; Santa Maria, Rio Grande do Sul, Brasil; gabrielquarairsbrasil@gmail.com

${ }^{3}$ Acadêmica em Educação Física Licenciatura;Universidade Federal de Santa Maria; Santa Maria, Rio Grande do Sul, Brasil; andressa.ufsm.lic@hotmail.com
} 
la realidad escolar, estimularon la búsqueda de metodologías adecuadas para amenizar tales dificultades como futuros profesores. De esta manera, se constató que la Docencia Orientada presenta un momento esencial en la formación inicial, contribuyendo a la apropiación de conocimientos acerca de la docencia en Educación Física con jóvenes y adultos, instigando la búsqueda por la calificación hacia la práctica docente así como el enfrentamiento de las dificultades evidenciado.

Palabras claves: Docencia; Educación Básica; Educación Física; EJA, Formación Inicial.

\begin{abstract}
The discipline of Teaching Oriented in Physical Education in the degree course of the Federal University of Santa Maria/RS (UFSM), provides to the academic the insertion in the school network and exercise of the teaching in front of the different educational contexts currently. In the specific case of Youth and Adult Education (EJA), teaching oriented in the degree of Physical Education of UFSM, seeks to bring the academic closer to the reality that we find in the current educational environment through the exercise of teaching. In this sense, the objective of this article seeks to analyze how Physical Education in the EJA contributes to the formation process of the academics. For this, we analyzed some practices experienced during the Discipline of Teaching Oriented in Physical Education in the EJA. Through the insertions in schools, the following difficulties were encountered: social problems, obstacles in contemplation, organization of contents due to different age groups, evasion, among others. These situations enabled the approach to the school reality, stimulated the search for suitable methodologies to ameliorate such difficulties as future teachers. In this way, it was verified that the Oriented Teaching presents an essential moment in the initial formation, contributing to the appropriation of knowledge about teaching in Physical Education with young people and adults, instigating the search for the qualification aiming at teaching practice as well as the confrontation of the difficulties evidenced.
\end{abstract}

Keywords: Teaching; Basic Education; Physical Education; EJA; Initial Formation.

\title{
1. Introdução
}

A Educação Física (EF) atualmente se configura como um dos componentes curriculares na rede básica de ensino, bem como as demais disciplinas do ambiente escolar o ponto inicial para o planejamento e o desenvolvimento do processo de ensino aprendizagem parte da reflexão crítica e realidade social em que a comunidade atendida pela instituição escolar se identifica, visando assim, adequação e qualificação do trabalho docente na busca do atendimento às demandas e necessidades dos sujeitos que participam do cotidiano escolar.

Desse modo, a Educação Física utiliza-se das manifestações e expressões culturais que compõem a cultura corporal (SOARES et. al. 2012), como instrumentos/meios deste processo, auxiliando na construção de uma formação integral dos alunos que se inserem no ambiente escolar.

Diante da atual conjuntura educacional, encontramos um elevado índice de evasão dos alunos, déficit de qualificação profissional, e uma limitação nas oportunidades de formação inicial. É imprescindível que o professor esteja qualificado para exercer a docência frente às diversidades que encontramos enquanto futuros professores de Educação Física, como evasão de alunos, infrequência, faixa etárias diversificadas, etc. 
RELACult - Revista Latino-Americana de Estudos em Cultura e Sociedade

É essencial que existam oportunidades às quais viabilizem aos acadêmicos, experienciar diferentes modalidades do ensino básico durante a formação inicial, proporcionando aos professores em formação, possibilidades de transformar dificuldades e práticas em conhecimentos, metodologias que sejam fundamentais para o exercício da docência diante as adversidades e dificuldades encontradas, resultando em um processo de qualificação advindo de experiências.

Deste modo, a disciplina de Docência Orientada ofertada no $7^{\circ}$ semestre do currículo do curso de Educação Física Licenciatura da Universidade Federal de Santa Maria (UFSM) tem por objetivo proporcionar aos alunos experiências/vivências, no sentido de possibilitar o exercício da docência para Jovens e Adultos na modalidade da EJA.

A EJA visa democratizar o acesso à formação básica, assim "a educação de jovens e adultos será destinada àqueles que não tiveram acesso ou continuidade de estudos nos ensinos fundamental e médio na idade própria e constituirá instrumento para a educação e a aprendizagem ao longo da vida"(BRASIL, 1996).

Sua trajetória histórica data da década de 40, período da industrialização (urbana) tardia no Brasil, os primeiros passos começam a ser dados pelo "gérmen" do que se tornaria a EJA atualmente, a primeira campanha nacional de alfabetização feita no país se efetivou buscando levar o desenvolvimento social e econômico à população a partir da educação.

No Brasil, a primeira iniciativa pública, visando especificamente o atendimento do segmento de adolescentes e adultos, ocorreu em 1947 com o lançamento da Primeira Campanha Nacional de Educação de Adolescentes e Adultos (CEAA), iniciativa do Ministério da Educação e Saúde e coordenada por Lourenço Filho (ALMEIDA E CORSO, 2015, p. 1286).

Este movimento estatal surge a partir da pressão de organismos internacionais recém criados (ONU, UNESCO) pós $2^{\text {a }}$ Guerra Mundial, que destacavam como causa do atraso das nações a ignorância da população resultando na limitação do desenvolvimento destes países. Durante a década de 50 ocorre o II Congresso Nacional de Educação de Adultos que se caracterizou por fazer críticas a campanha nacional apontando suas debilidades:

A precariedade dos prédios escolares, a inadequação dos métodos de ensino e a falta de qualificação profissional do professor de adultos [...] a necessidade de uma maior comunicação entre educador e educando; e a necessidade de adequação dos conteúdos e métodos de ensino às características socioculturais das classes populares (ALMEIDA E CORSO, 2015, p. 1288).

A fragilidade da educação pública se torna uma importante pauta na luta civil do país no início dos anos 60, conjuntamente com esse cenário, iniciativas populares de alfabetização obtiveram grande repercussão social, segundo Strelhow (2010, p. 54) “esses movimentos, 
procuravam reconhecer e valorizar o saber e a cultura popular, considerando assim, a pessoa não alfabetizada uma produtora de conhecimento", já na esfera institucional essa luta resultou na indicação de Paulo Freire até então um dos líderes do movimento de alfabetização no país para ser um dos mentores do Plano Nacional de Alfabetização.

Este processo se interrompe em 1964 com o golpe militar instalado no Brasil, muitos dirigentes de movimentos sociais são presos, e a EJA nos primeiros anos da ditadura desaparece das políticas do governo. A primeira política do regime para a EJA data de 1967, o Movimento Brasileiro de Alfabetização (MOBRAL) "com o objetivo de alfabetizar funcionalmente e promover uma educação continuada. Com esse programa a alfabetização ficou restrita à apreensão da habilidade de ler e escrever" (STRELHOW, 2010, pg. 54).

Em 1971 ainda durante o regime militar, a Lei de Diretrizes e Bases da Educação (BRASIL,1971) garantia o ensino para crianças de 7 à 14 anos mesmo reconhecendo a Educação de Adultos como direito a cidadania, mas não garantindo meios para um ensino de qualidade. Esse cenário começa a mudar com a promulgação da Constituição Federal de 1988, onde a educação passa a ser direito de todos os cidadãos, bem como, a LDB/96 em artigo $4^{\circ}$ que garante o acesso público e gratuito ao ensino fundamental e médio para todos que não concluíram na idade própria (BRASIL, 1996).

Mais recentemente alguns programas foram criados para auxiliar no desenvolvimento da EJA na rede pública, como por exemplo, o Programa Nacional de Integração da Educação Profissional com a Educação Básica na Modalidade de Educação de Jovens e Adultos (PROEJA) de $2005^{4}$, que tem por objetivo ofertar a educação profissional técnica de nível médio aos alunos.

Já no viés econômico, o marco mais contemporâneo que diz respeito ao financiamento da modalidade, bem como, da educação básica como um todo é o Fundo de Manutenção e Desenvolvimento da Educação Básica e de Valorização dos Profissionais da Educação (FUNDEB), que cria um fundo especial para ser utilizado exclusivamente no financiamento e valorização dos trabalhadores da educação básica (BRASIL, 2007).

A partir do atual contexto em que a EJA se apresenta na rede escolar este trabalho tem por centralidade abordar as experiências docentes na EJA e como esta vivência contribuiu no processo formativo inicial dos acadêmicos, refletindo assim, sobre a realidade e possibilidades que encontramos enquanto docente com o público escolar da EJA.

\footnotetext{
${ }^{4}$ Dísponível para acesso em: http://portal.mec.gov.br/proeja.
} 
Inicialmente, relatamos sobre as experiências (vivências) docentes advindas da intervenção nas escolas públicas com o público da EJA, posteriormente, debatemos as possibilidades e realidades enfrentadas na rede escolar, e de que forma essas experiências nos auxiliaram no processo de formação inicial.

\section{Docência Orientada na EJA: Organização e viabilização da docência}

A disciplina de Docência Orientada em Educação Física, promove a inserção do acadêmico na rede escolar, possibilitando superar alguns dos desafios que encontramos na educação básica, como a dificuldade em trabalhar conteúdos diversificados, os quais contemplem diferentes faixas etárias dentro de uma mesma etapa de ensino.

A referida disciplina foi organizada com discussões e debates com fundamentações teóricas sobre o exercício da docência, aplicação de conhecimentos, formação de atitudes e desenvolvimento de habilidades necessárias à prática docente. Foram ainda organizados seminários com professores em exercício na EJA, dinâmicas em grupos baseadas em resumos e cronologias da história nessa modalidade de ensino, realizados no Centro de Educação Física e Desportos da Universidade Federal (CEFD), espaços esses que oportunizaram aos acadêmicos debates sobre a atual conjuntura da EJA.

Os encontros presenciais se configuraram em um momento ímpar para a formação inicial dos acadêmicos, proporcionando reflexões críticas acerca do entendimento do que é a EJA, embasados nos Parâmetros Curriculares em Educação Física (PERNAMBUCO, 2013) entre outros documentos legais, filmes voltados a temática, debates, entre outros. Correlacionando esses documentos às realidades encontradas no exercício da docência orientada na EJA.

A disciplina tem como objetivo a inserção dos acadêmicos na rede escolar, visando uma aproximação dos acadêmicos com as equipes diretivas, professores e alunos das escolas, através de uma apresentação inicial da proposta de intervenção, seguida pela realização da docência em escolas públicas de diferentes regiões do município de Santa Maria, RS. As intervenções foram realizadas sob supervisão dos professores regentes da escola, totalizando oito aulas, com turmas de ensino fundamental e médio na modalidade da EJA.

Neste estudo, priorizando os aspectos éticos optamos por denominar as duas escolas públicas onde a prática docente foi realizada pela caracterização de escola $\mathrm{A}$ e $\mathrm{B}$, bem como as turmas por siglas T1, T2 e T3.

Na escola A, o trabalho de intervenção foi desenvolvido com uma turma (T1referente ao $7^{\circ}$ ano do ensino fundamental), e na escola $\mathrm{B}$, a intervenção foi realizada em duas 
turmas ( T2 e T3- equivalente ao $2^{\circ}$ e $3^{\circ}$ ano do ensino médio). As aulas eram ministradas em duplas, critério estabelecido pela professora regente da disciplina de Docência Orientada em Educação Física.

Os acadêmicos tiveram a liberdade de escolha para realização da intervenção, como também prazos a serem cumpridos com questões de documentação burocráticas a serem entregues. A opção pela escola A, motivou-se pelo conhecimento e contato prévio por parte dos estagiários com o professor regente da instituição, bem como o trabalho desenvolvido anteriormente durante as aulas de EF por intermédio do estágio supervisionado. Em relação a escola B, optou-se pela instituição devido às boas referências obtidas anteriormente, sobre espaços físicos, materiais disponíveis e uma gestão atuante que proporciona ações positivas para o público da EJA da escola advinda de colegas, bem como conversa posterior com a professora regente sobre o trabalho desenvolvido na escola e sua metodologia de ensino.

Neste viés, a partir das informações coletadas durante as observações, foram realizadas trocas de informações sobre as turmas entre os acadêmicos e supervisores, norteando a elaboração dos planos de ensino e conteúdos, de modo que fornecessem um aprendizado significativo aos alunos. Diante disso, foram considerados a média de frequência dos alunos, a proporção quantitativa por gênero e as preferências de atividades dentro do contexto no qual os alunos estão inseridos.

Considerou-se ainda o planejamento dos professores regentes, Projeto Político Pedagógico (PPP) da escola e Diretrizes Comuns Curriculares (DCNs), o que nos auxiliou no processo de construção dos planos de ensino, tendo como objetivo, sistematizar os conteúdos que seriam aplicados, perante as diferentes turmas em que a docência seria realizada, de forma que o ensino atendesse a diversidade do público da EJA. Desta maneira os conteúdos tematizados foram o voleibol, futsal e handebol, utilizando como critério para a escolha dos conteúdos se deu pelo fato de já estar sendo desenvolvido pelo professor nas aulas e o segundo pelo princípio curricular da relevância social do conteúdo (SOARES et. al., 2012).

Visto as diferentes realidades escolares e de adaptação da disciplina de EF a este contexto optou-se por diferentes abordagens (Crítico Superadora e Desenvolvimentista) e distintos conteúdos para que pudéssemos oferecer aos alunos uma proposta motivadora para o ensino da EF.

Percebemos em todas as turmas trabalhadas um grande número de alunos matriculados, porém com um grande índice de alunos infrequentes. A faixa etária desses alunos no ensino fundamental, variou entre 16 e 40 anos, enquanto que no ensino médio faixa etária tramitou entre 18 e 35 anos. 
Por este viés o referencial teórico utilizado para a preparação das aulas, corrobora para os critérios de escolha dos conteúdos que embasam o trabalho pedagógico na escola, assim optou-se pela "perspectiva de uma pedagogia crítico superadora aqui defendida, deve fazer uma seleção dos conteúdos da Educação Física. Essa seleção e organização de conteúdos exige coerência com o objetivo de promover a leitura da realidade"(SOARES, et. al., 2012, p. $63)$.

Como aporte metodológico para a organização e desenvolvimento das aulas foi empregado o 'método dos cinco passos' (SAVIANI, 2012). Segundo MENGER e VALENÇA (2012, p. 509),esses passos podem ser sintetizados da seguinte maneira:

$1^{\circ}$ : ponto de partida é a prática social, comum a professores e alunos.

$2^{\circ}$ : problematização - detectar que questões precisam ser resolvidas no âmbito da prática social.

$3^{\circ}$ : apropriação de instrumentos teóricos e práticos para resolver os problemas detectados é o que Saviani chama de instrumentalização.

$4^{\circ}$ : catarse: incorporação dos instrumentos culturais transformados em elementos ativos em transformação social.

$5^{\circ}$ : própria prática social. É a elevação dos alunos ao nível do professor para se compreender a especificidade das relações pedagógicas.

A partir desta metodologia entende-se que no primeiro momento é a prática social comum a ambos os sujeitos presentes na aula, mas o que diferencia é a compreensão (síntese precária ou complexa) sobre este fenômeno social, assim o segundo passo visa problematizar questões pertinentes ao processo de ensino recrutando um novo conhecimento necessário para contemplar tais problemas já levantados. O terceiro momento a instrumentalização, objetiva apropriar-se desse novo conhecimento (instrumentos teóricos e práticos) recrutado na problematização que encaminha ao quarto passo a catarse, que pode ser compreendida como a incorporação e transformação destes novos conhecimentos em elementos ativos na execução da prática social (quinto passo) que será efetivada com um nível de síntese mais apurado do que no início do processo de ensino (SAVIANI, 2012).

A partir desta concepção educacional, os objetivos traçados estiveram pautados em proporcionar o ambiente rico para o apoderamento do conhecimento tematizado dentro dos conteúdos abordados, tornando as aulas menos centralizadas na figura do professor valorizando o ponto de vista dos alunos e consequentemente constituindo discussões a partir das diferentes compreensões acerca da cultura corporal.

A abordagem desenvolvimentista, segundo Go Tani (1988) busca nos processos de aprendizagem e desenvolvimento uma fundamentação para a Educação Física escolar, sendo caracterizada com uma tentativa a progressão normal do crescimento físico, do 
desenvolvimento fisiológico, motor, cognitivo e afetivo social, na aprendizagem motora e, em função destas características, sugere a elementos relevantes para a estruturação da EFE.

Assim, o principal objetivo da EF é oferecer experiências de movimento adequadas ao seu nível de crescimento e desenvolvimento, a fim de que a aprendizagem das habilidades motoras sejam alcançadas, de acordo com o estágio de transferência de cada aluno e suas limitações.

Tais abordagens possuem um papel fundamental no processo de organização e sistematização dos conteúdos aplicados, de modo que proporcionam um aporte teórico sobre os conhecimentos específicos da EF de forma sistematizada facilitando o processo de ensinoaprendizagem.

\section{Análises e Reflexões da experiência docente}

O trabalho docente com o público da EJA a partir da inserção pedagógica proposta na disciplina de Docência Orientada resultou em um momento muito significativo no processo de formação inicial, devido às disparidades das realidades concretas que a modalidade apresenta cotidianamente, nada parecido com às experiências anteriores que a formação inicial oportunizou nos estágios supervisionados.

Uma das principais semelhanças entre as turmas onde as intervenções pedagógicas foram desempenhadas, foi o número significativo de alunos trabalhadores, entre eles, jovens com idade mínima para ingresso na modalidade, ou seja, quinze anos para o ensino fundamental e 18 anos para o ingresso no Ensino Médio (BRASIL, 1996).

A maior parte destes alunos, migraram do Ensino regular para a modalidade EJA por questões de oportunidades de conciliação do trabalho com os estudos, da mesma maneira, trabalhadores adultos com idade mais avançada, que por vários motivos não completaram seus estudos em tempo regular e retornaram a escola.

\footnotetext{
Nesse sentido, não se refere a qualquer jovem ou adulto, mas delimita um determinado grupo de pessoas, relativamente homogêneo, que vivenciam variadas situações de produção da existência na sociedade contemporânea, mas quase todas elas ligadas, no mundo do trabalho (VENTURA, 2012, p.78 e 79).
}

Ao iniciarmos a regência, encontramos dificuldades de organização para a contemplação dos conteúdos devido a diversidade de faixa etária encontrada nas turmas, como também preocupação em relação ao número massivo de evasão dos alunos, talvez justificada pela longa jornada de trabalho vivenciada pela maioria dos alunos. Deste modo, 
surgiram desafios no processo de execução dos planejamentos, sistematização e apropriação dos conteúdos referentes aos níveis de ensino.

Neste sentido a formação inicial durante o processo formativo, negligência momentos ímpares onde possamos abordar realidades tão peculiares como se demonstra a modalidade da EJA. A realidade muitas vezes das instituições responsáveis pela preparação de futuros professores para desempenhar o trabalho docente em condições quase que perfeitas, mas não condizentes a realidade escolar brasileira que encontramos na atual conjuntura educacional.

A maioria dos cursos de formação de professores nos prepara para atuar com o aluno ideal - por que não dizer irreal. Aprendemos os conteúdos de nossas áreas, conhecemos algumas ferramentas pedagógicas e metodológicas, mas estamos longe de pensar a realidade concreta da escola (MACHADO, 2008, p. 165).

Deste modo, salientamos novamente a extrema importância deste espaço no processo de formação inicial, pois não sabemos como proceder mediante tais dificuldades evidenciadas, devido a precariedade de debates e oportunidades que visem de auxiliar a prática docente para enfrentamento de situações adversas como as evidenciadas.

\section{Considerações Finais}

O período de intervenção pedagógica, embora rápido, foi extremamente significativo no processo formativo no sentido do que é "ser professor". O aprendizado neste período foi mútuo, pois o ambiente escolar proporcionou a troca entre levar o conhecimento já adquiridos até os alunos, mas também obter novos aprendizados com os mesmos.

Apesar da experiência sabemos que a formação docente necessita ser uma construção contínua e diária de saberes, sejam eles teóricos (conceituais e metodológicas) e práticos (didáticos), buscando contemplar assim as demandas do ambiente escolar onde estamos inseridos futuramente, de modo que possamos enfrentar de forma qualificada as dificuldades evidenciadas.

O exercício da docência orientada nas escolas, contribui no processo de formação, de forma a qualificar o trabalho docente, estreitando as relações e possibilidades de diálogo entre acadêmicos e supervisores,.

Apesar de termos trabalhado com diversos conteúdos, notamos que ainda existe uma grande dificuldade de como organizar e sistematizar os conteúdos da EF na EJA, uma vez que devemos considerar a flexibilização das atividades em prol do número de alunos frequentes, condições físicas e psíquicas dos estudantes, com o propósito de possibilitar aos mesmos 
condições de ensino de qualidade, para que esses conteúdos sejam internalizados com êxito, sendo significativos para o sujeito.

\section{Referências}

ALMEIDA, A.; CORSO, A. M. A educação de jovens e adultos: aspectos históricos e sociais. In: Congresso Nacional de Educação, 12. 2015, Curitiba. Anais http://educere.bruc.com.br/arquivo/pdf2015/22753_10167.pdf. Curitiba, 2015.

BRASIL. Câmara dos Deputados. Lei de Diretrizes e Bases no 5692 de 11 de agosto de 1971. Fixa Diretrizes e Bases para o ensino de $1^{\circ}$ e $2^{\circ}$ graus. Brasília, DF, 1971. Disponível em: http://www2.camara.leg.br/legin/fed/lei/1970-1979/lei-5692-11-agosto-1971-357752publicacaooriginal-1-pl.html.

BRASIL. Ministério da Educação. Fundo de Manutenção e Desenvolvimento da Educação Básica e de Valorização dos Profissionais da Educação, Lei $n^{\circ} 11494$ de 20 de Junho de 2007. Regulamenta o Fundo de Manutenção e Desenvolvimento da Educação Básica e de Valorização dos Profissionais da Educação - FUNDEB. Brasília, DF, 2007. Disponível em: http://www.planalto.gov.br/ccivil_03/_Ato2007-2010/2007/Lei/L11494.htm.

BRASIL. Ministério da Educação. Lei de Diretrizes e Bases da Educação $n^{\circ} 9394$ de 20 de Dezembro de 1996. Estabelece as diretrizes e bases da educação nacional. Brasília, DF, 1996. Disponível em: http://www.planalto.gov.br/ccivil_03/LEIS/L9394.htm.

MACHADO, M. M. Formação de professores para EJA: uma perspectiva de mudança. Revista Retratos da Escola, v. 2, n. 2-3, p. 161-174, jan./dez. 2008. ISSN 2238-4391. Disponível em: http://retratosdaescola.emnuvens.com.br/rde/article/view/133/235. Acesso em: 10 jan. 2019.

MENGER, A. S.; VALENÇA, V. L. C. A pedagogia histórico-crítica no contexto das teorias de educação. POIÉSIS - Revista do Programa de Pós-Graduação em Educação - Mestrado Universidade do Sul de Santa Catarina, v. 6, n. 10, p. 497-523, jul./dez. 2012. ISSN 21792534. http://www.portaldeperiodicos.unisul.br/index.php/Poiesis/article/view/1321/1072. Acesso em: 14 jan. 2019.

PERNAMBUCO. Secretaria de Educação. Parâmetros Curriculares de Educação Física: Educação de Jovens e Adultos. Recife, PE, 2013. Disponível em: http://www.educacao.pe.gov.br/portal/upload/galeria/4171/PCPE_VD_EDUCACAO_FISICA EJA.pdf.

Portal do Ministério da Educação (MEC). Dísponivel em: http://portal.mec.gov.br/proeja. Acesso em: 11 jan. 2019.

SAVIANI, D. Escola e democracia. São Paulo: Autores Associados, 2012. 94 p.

SOARES, C. L. et. al. Metodologia do ensino de educação física. São Paulo: Cortez, 2012. $119 \mathrm{p}$.

STRELHOW, T. B. Breve história sobre a educação de jovens e adultos no Brasil. Revista HISTEDBR On-line, n.38, p. 49-59, jun. 2010. ISSN 1676-2584. Disponível em: https://periodicos.sbu.unicamp.br/ojs/index.php/histedbr/article/view/8639689/7256. Acesso em: 12 jan 2019. 
TANI G. et .al. Educação Física Escolar: fundamentos de uma abordagem desenvolvimentista. São Paulo: Editora da Universidade de São Paulo, 1988.

VENTURA, J. A EJA e os desafios da formação docente nas licenciaturas. Revista da FAEEBA - Educação e Contemporaneidade, v. 21, n. 37, p. 71-82, jan./jun. 2012. ISSN 01047043. Disponível em: https://www.revistas.uneb.br/index.php/faeeba/article/view/458/398. Acesso em: 14 jan. 2019. 